\section{The Vatican and embryology}

SIR-As a developmental biologist and a Roman Catholic, I would like to make some comments on your leading article "The Vatican and embryology" ( Nature 326, $229 ; 1986)$. The article correctly points out the two principles applied by the Instruction of the Catholic Church: life of individual human beings shall be respected absolutely and sexual acts and procreation must be reciprocally connected. The document implicitly applies another basic principle underlying and justifying the previous two. It is, that man is more than an exhaustive addition of experimental data; man is more than its functioning. This is a basic issue, pre-ceding the consideration of any research data on man's functioning. One can argue classically that what cannot be studied by science is not scientific, but non-scientific does not mean irrelevant.

Establishing the moment when an individual unborn human being becomes a human person, that it has the same rights as a born human baby, is not a matter of natural sciences, unless one can demonstrate a physio-chemical or biological structure underlying human rights. Most people agree that it is the more that provides the criteria for solving the issue. The Catholic Church too agrees to this proposal. And in applying its more, considers correctly that its conclusions are not rejected by research data, which have exhaustively shown individuality to be definitely fixed with the fusion of the two haploid gametes. Logically, the Catholic Church also discourages additional research on human (embryonic) persons for the purpose of reaching a better understanding of their functioning for the simple reason that embryos are already people: research comes too late, and its only contribution to that unique human person would probably be its death.

Looking at a similar issue in the past, human slaves did not have to wait for a better understanding of man's functioning to show that they were similar to human non-slaves. Fortunately for them and for us, they were finally recognized to be human persons. Looking at the future, we have to be careful that other old, mentally ill or undesired human beings do not again lose their rights either with the complicity of science or in its name.

Setting no limits for science other than science itself, as the article implicitly claims, is neither scientific, because it is basically a pre-scientific choice, nor acceptable because the only limits would be the scientifically and technically possible. And despite the many marvellous achievements of science, we have enough examples of horrors that science can cause, both under control (Dresden, Hiroshima and Nagasaki, Gulag) and out of control (thalidomide, Seveso, Spanish oil, Bhopal, Chernobyl). The reasonable limit proposed by the Catholic Church respects what man is.

P. JUNQUERA

CIBA GEIGY,

Centre de recherches agricoles,

1566-St-Aubin, Switzerland

SIR-Your leading article "The Vatican and embryology" ( Nature 326, 229; 1987) indicates that the writer does not (or does not want to) understand people who believe in the eternal life of every human individual.

The resurrection of Christ is the basis, in reality the only basis, of the Christian faith. If there is no eternal life, scientists as well as militarists, industrial managers or political powers may do with human beings what they want. No man-made agreement will be able to establish common human standards of conduct. Future generations may have to live with multiple variations of 'holocausts'.

Salmannsdorfer Str. $94 c$

Alexander Micke

A-1190 Vienna, Austria

SIR-One of your major arguments against the Vatican Instruction on in vitro fertilization warrants comment.

The point is made that "in laboratories, for example, it is important to know when the development of artificially fertilized embryos must be stopped for fear of accumulating unwanted and inviable human individuals in Petri dishes". You go on to suggest that it would also have been prudent on the part of the Church not to have taken an absolute stand in defending the inviolability of the life of the embryo from the moment of conception, as experimental evidence may some day be forthcoming that will allow us to say with certainty at what point in its development it becomes a new human individual.

The argument applies even more strongly in reverse. If one is in doubt as to when one can say that a new human individual is present, and if one holds "that the lives of individual human beings should be respected absolutely", the prudent course is to treat the embryo with absolute respect from the moment of conception.

An analogy, perhaps somewhat crude, with the question of when an embryo should be accorded the respect due to a human being may be drawn with an aspect of my growing up in farm country in western Canada. When we were young, we used to go hunting with rifles or shotguns. But, in addition to teaching us the technicalities of how to use the guns, our parents thoroughly inculcated us with an elementary lesson of prudence to avoid accidentally shooting another person. It was to the effect that we must never shoot at a movement or a figure unless we were absolutely sure it was not a person. Lack of obedience to this simple principle was (and still is) responsible for many hunting accidents and deaths. (In this, I prescind from the debate over hunting for sport, which I have not done for over 30 years.)

This argument also applies to the opposition, from the Roman Catholic Church and others, to clinical abortion at any stage of pregnancy, namely that one cannot take the risk that one may be killing an innocent human being.

JOSEPH G. ATKINSON

Merck Frosst Canada Inc.,

CP/PO 1005, Pointe-Claire-Dorval, Quebec H9R 4PE, Canada

\section{What Fisher meant}

SIR-The basis for thinking that R.A. Fisher would have approved the optimization methods underpinning the modern evolutionary approach to biology ${ }^{1}$ is his statement ${ }^{2}$ that: "The vital statistics of an organism in relation to its environment provide a means of determining a measure of the relative growth-rate of the population, which may be termed the Malthusian parameter of population increase . . The Malthusian parameter will in general be different for each different genotype, and will measure the fitness to survive of each ... Any net advantage gained by an organism will be conserved in the form of an increase in population, rather than in an increase in the average Malthusian parameter, which is kept by ... adjustment always near to zero." Fisher must have meant 'gene' when he wrote 'genotype' because the proof ${ }^{3}$ depends on that. Thus inferior genes are removed from the population and those left maximize the Malthusian parameter.

This process is subject to constraints, as Fisher well knew when he wrote the oftenquoted words ${ }^{2}$ that "it would be instructive to know not only by what physiological mechanism a just apportionment is made between the nutriment devoted to the gonads and that devoted to the rest of the parental organism; but also what circumstances in the life-history and environment would render profitable the diversion of a greater or lesser share of the available resources towards reproduction". Thus did Fisher provide the twin principles, of fitness maximization, but subject to constraints, which underpin the optimization approach.

R.M. SIBLY

Department of Pure and Applied Zoology, University of Reading,

Reading RG6 $2 A J, U K$

1. Edwards, A.W.F. Nature 326, 10 (1987).

. Fisher, R. A. The Genetical Theory of Natural Selection, 2nd edn (Dover, New York, 1958)

3. Sibly, R.M. \& Calow, P. Physiological Ecology of Animals (Blackwell, Oxford 1986). 